\title{
Effectiveness of a redesigned iron supplementation delivery system for pregnant women in Negros Occidental, Philippines
}

\author{
Maria Grace D Risonar ${ }^{1, *}$, Pura Rayco-Solon ${ }^{1}$, Lorena W Tengco ${ }^{1}$, Jesus N Sarol Jr², \\ Lourdes S Paulino ${ }^{3}$ and Florentino S Solon ${ }^{1}$ \\ ${ }^{1}$ Nutrition Center of the Philippines, Social Science Research Division, Villamor Interchange, South \\ Superhighway, Western Bicutan, Taguig City 1630, Philippines: ${ }^{2}$ College of Public Health, University of the \\ Philippines, Manila, Philippines: ${ }^{3}$ National Center for Disease Prevention and Control, Department of Health, \\ Manila, Philippines
}

Submitted 21 August 2007: Accepted 8 July 2008: First published online 27 August 2008

\begin{abstract}
Objective: To determine the effectiveness of a redesigned Fe supplementation delivery system (ISDS) in improving $\mathrm{Hb}$ concentrations and compliance among pregnant women.

Design: A controlled before and after study design was used. Interviews and $\mathrm{Hb}$ measurements of randomly selected pregnant women in both treatment areas were conducted at baseline and after 6 months. The redesigned ISDS, reached by consensus based on the surveys and focus group discussions, involved the health workers in spot mapping and clustering; Fe tablets' distribution, monitoring and promotion; and counselling of pregnant women.

Setting: Negros Occidental and Negros Oriental, Philippines.

Subjects: In total, 1180 pregnant women given Fe/folic acid tablets daily through the redesigned ISDS in the experimental areas and the existing ISDS in the control areas.

Results: There were significantly more anaemic pregnant women in the experimental than in the control area at baseline $(50 \cdot 7 v \cdot 37 \cdot 3 \% ; P=0 \cdot 001)$. However, at endline, the anaemia prevalence rate in the experimental area was comparable to that of the control $(35.6 v \cdot 33 \cdot 1 \% ; P=0.530)$. Also, the mean $\mathrm{Hb}$ concentration increased significantly in the experimental area by $0.5 \mathrm{~g} / \mathrm{dl}(P=0.002)$. An increase in the actual number of prenatal visits/trimester in the experimental area was observed (from 0.99 to $1.66 ; P<0.0001$ ). Pregnant women in the experimental area were four times more likely to take Fe tablets (OR $=3 \cdot 79 ; P<0 \cdot 001)$ and sixteen times more likely to being monitored for Fe intake $(\mathrm{OR}=16 \cdot 86$; $P<0 \cdot 001)$ compared to the control.

Conclusions: The redesigned ISDS was effective in improving the $\mathrm{Hb}$ concentration and health-related behaviour of pregnant women.
\end{abstract}

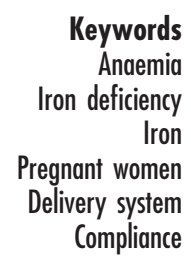

Globally, Fe deficiency and anaemia remain major public health problems. The global prevalence of anaemia among pregnant women is $41 \cdot 8 \%$, more prevalent in the developing regions of Africa $(55 \cdot 8 \%)$ and Asia $(41 \cdot 6 \%)^{(1)}$. In the Philippines, anaemia prevalence among pregnant women remains high as shown in the National Nutrition Surveys in $1993(43 \cdot 6 \%), 1998(50 \cdot 7 \%)$ and $2003(43 \cdot 9 \%)^{(2-4)}$. The risk of developing Fe deficiency anaemia (IDA) is highest during pregnancy because the amount of dietary Fe absorbed cannot meet the increased demand for Fe. During pregnancy, Fe requirements increase by the second trimester, and by up to $5-6 \mathrm{mg}$ per day during the last trimester ${ }^{(5)}$. A varied array of interventions that include dietary improvement, fortification of food with $\mathrm{Fe}$, Fe supplementation and other public health measures, such as helminth control, have been designed to prevent and correct IDA ${ }^{(6-9)}$. Fe supplementation remains the most widely used approach to meet the elevated physiological Fe demands of pregnant women ${ }^{(9)}$. However, the effectiveness of this approach has been limited due to inefficient health services, which includes inadequate supply and sub-standard $\mathrm{Fe}$ supplements resulting in low compliance of pregnant women ${ }^{(10-13)}$.

The effectiveness of an Fe supplementation programme depends to a large extent on the delivery system and the recipients' compliance. The availability of Fe tablets in the health centres relies in turn on the government's policy, funds from the local government units and the available infrastructure. Community communication to encourage programme participation and partnership is essential when 
tackling the Fe supply and demand problems and to ensure programme sustainability and success ${ }^{(9)}$. In addition to ensuring the adequacy of Fe supply, health workers must be trained on anaemia and on the importance of Fe during pregnancy, and motivated to comply with the set protocol to ensure that pregnant women receive the required Fe tablets.

The receipt of sufficient Fe tablets, however, will not ensure that pregnant women will actually take them as required ${ }^{(14)}$. Compliance is influenced by the undesirable side effects brought about by the ingestion of Fe tablets, which are related to the amount ${ }^{(15)}$ and form of the tablets ${ }^{(8)}$ and possibly to the frequency and duration of its ingestion. Further, the knowledge, attitudes and practices of the pregnant women regarding the use of $\mathrm{Fe}$ tablets are important factors to consider ${ }^{(16,17)}$. At present, prenatal Fe supplementation programmes in developing countries have been unable to achieve good coverage and have been ineffective in reducing anaemia among pregnant women ${ }^{(18)}$ Efforts are needed to determine innovative solutions to the problems in the supply and distribution of $\mathrm{Fe}$ tablets, adherence of pregnant women to Fe supplementation and reduction of concurrent infections (malarial and parasitic). A successful Fe supplementation programme for pregnant women would eventually benefit the mother and the child through increased productivity, improved quality of life and increased physical and mental performance.

The present study was conducted to determine the effectiveness of the redesigned $\mathrm{Fe}$ supplementation delivery system (ISDS) for pregnant women in improving Fe status, reducing anaemia prevalence, increasing compliance of pregnant women and in upgrading coverage by the health workers.

\section{Methods}

\section{Study area and participants}

The present study was carried out in the two provinces of the island of Negros in Southern Philippines. The province of Negros Occidental was the experimental area with $63.4 \%$ anaemia prevalence among pregnant women prior to the study ${ }^{(3)}$. The province of Negros Oriental was selected as the control area because of its similarity with the experimental area in terms of socio-economic status and geographical features. Schistosomiasis and malaria are not endemic in both provinces. From each province, three areas were chosen to represent different socio-developmental standings as set by the Philippine Department of Finance, namely one upper class city, one middle class city and one lower class municipality. Three villages were selected from each area based on geography (one coastal and two hinterland) and population size. The study sample was representative of the two provinces in Negros island and its coastal and hinterland cities and barangays in terms of sociodemographic parameters.
Approximately 288 pregnant women at baseline and at post-six months were required for each treatment group based on the following assumptions: $60 \%$ baseline anaemia prevalence, $20 \%$ reduction in anaemia prevalence with $80 \%$ statistical power and an alpha of 0.05 . The sample size was increased by $5 \%$ to account for possible dropouts; hence, 300 pregnant women per treatment group per survey period were needed or a total of 1200 pregnant women. The EpiInfo software was used in generating the required sample size.

Before the baseline and endline surveys, pregnant women were identified using the Target Client List (TCL) in the government health units and the prenatal record books in private clinics. Those who were confirmed pregnant during house-to-house listing by the health workers were considered eligible for inclusion in the study. Pregnant women were randomly selected from the list at baseline and then again after 6 months. Thus, the pregnant women who participated at baseline were not the same pregnant women examined after 6 months. The number of pregnant women selected from each area was proportional to the population size of the village.

The age of gestation of each pregnant woman was determined based on the date of her last menstrual period (LMP). Of the $2.9 \%$ pregnant women whose LMP was unknown, a professional health worker measured the height of the uterine fundus to provide a rough estimate of the age of gestation. However, only gestational ages from LMPs were used in the analyses.

\section{Study design}

The first phase of the study was the evaluation and redesigning of the existing ISDS. The redesigned ISDS strategy was reached by consensus based on the results of a survey on the existing ISDS followed by focus group discussions among experts with inputs from village health workers (VHW) and traditional birth attendants (TBA). The second phase of the study focused on determining the effectiveness of the redesigned ISDS through a controlled trial.

A controlled before and after study design was chosen for the present study since the management of health programmes in the Philippines including Fe supplementation delivery was devolved to the local government units $^{(19)}$. In addition, inter-local health zones composed of provincial and municipal governments together with non-government organisations meet monthly aiming to improve health services delivery. Thus, individual or cluster (by village or municipality) randomisation within a province would not have been possible without contamination of interventions.

Interviews and $\mathrm{Hb}$ measurements of randomly selected pregnant women in both treatment areas were conducted at baseline and after 6 months of the installation of the redesigned ISDS in the experimental area. The health workers in both treatment areas were not blinded on the 
Fe status of the pregnant women. The participants were informed of their Fe status by the VHW.

\section{Intervention}

The intervention consisted of providing UNICEF tablets (Lomapharm, Germany) containing $60 \mathrm{mg}$ elemental Fe and $0.40 \mathrm{mg}$ folic acid to all pregnant women to be taken once daily in both treatment areas. The Department of Health (DOH) provided the UNICEF tablets that were used in the study. Adequate and regular Fe supply is an important component of success of any Fe supplementation programme. This problem had been cited during the preliminary survey on the existing ISDS and during the focus group discussions among health workers and experts. To eliminate the Fe supply as a confounding factor in the present study, a 2-year supply of Fe/folic acid tablets was delivered by the Philippine $\mathrm{DOH}$ to the Provincial Health Offices of both treatment areas following their routine supply and delivery procedures, prior to the training of the health workers. The one-week training of health workers on the features of the redesigned ISDS was conducted only in the experimental area.

The redesigned ISDS was installed and implemented in the experimental villages by the trained health workers while the existing ISDS was continued in the control villages. No incentive in cash or in kind was provided by the research team to the health workers in both treatment areas for their participation in the study.

The features of the redesigned ISDS included involvement of the VHW and the TBA in spot mapping and clustering to identify and register the pregnant women for antenatal care early; in the distribution of Fe supplements and monitoring of compliance using the monitoring notebooks; and in using information, education and communications (IEC) materials such as posters and flyers for promoting Fe supplementation in the community and for counselling pregnant women. All of these features were absent in the existing ISDS. The comparison of the existing ISDS and the redesigned ISDS is shown in Table 1.

A yearly household survey in each village was conducted by the VHW and TBA, the output of which was a village spot map wherein demographic information of the surveyed households was pictorially illustrated in a map of the community (usually drawn on the wall of the health centre) to give the local authorities the complete picture or profile of a locality in terms of age group, sex, physiologic status (pregnant, non-pregnant, child, father, etc.), socio-economic status, health and nutritional status at a glance. Clusters composed of twenty to thirty households were created, each managed by a VHW or TBA.

The pregnant women in the control area were given the UNICEF Fe/folic acid tablets using the existing ISDS while those in the experimental area were given the same tablets and dose using the redesigned ISDS. The Fe tablet distributors in the redesigned ISDS were the rural health midwife (RHM), VHW and the TBA. The first thirty Fe/ folic acid tablets were given by the RHM during the pregnant woman's first prenatal visit. The VHW and the TBA conducted home visits $15 \mathrm{~d}$ later and every $15 \mathrm{~d}$ thereafter to counsel, check the participants' compliance to Fe tablet intake and replenish their Fe supply. The fifteen extra Fe tablets given by the VHW and TBA served as a buffer supply until the pregnant woman's next prenatal visit. Compliance monitoring was conducted also by the RHM during the pregnant woman's prenatal visit in the health units. The remaining Fe tablets were counted and the intake was recorded in the TCL by the RHM and in the monitoring notebooks by the VHW and the TBA. During the distribution, counselling on the importance of Fe supplements during pregnancy and on dealing with the side effects after Fe tablet intake were also carried out by the RHM during mother's class and by the VHW and TBA during home visits using the IEC materials. Instructions on the dosage and frequency of intake (written in the label of the Fe packs) were also imparted to the pregnant women.

\section{Data collection}

Blood sample collection and interviews of pregnant women were conducted simultaneously in both treatment areas at baseline (June 2002) and at endline (January 2003). Blood samples were collected by trained medical technologists through finger-prick to determine $\mathrm{Hb}$ concentration on-site using a HemoCue hemoglobinometer (HemoCue, Sweden) following standard procedures. Anaemia was defined as $\mathrm{Hb}<11 \mathrm{~g} / \mathrm{dl}$. Anaemia was further

Table 1 Comparison of the existing ISDS and the redesigned ISDS

\begin{tabular}{|c|c|c|}
\hline Features & Existing ISDS & Redesigned ISDS \\
\hline Spot map & Spot map not updated & Spot map updated \\
\hline Clustering & Absent/inactive clusters & Organised/active clusters \\
\hline \multirow[t]{3}{*}{ Fe tablet distributors } & Rural health midwife & Rural health midwife \\
\hline & & Village health workers \\
\hline & & Traditional birth attendants \\
\hline IEC materials for counselling & No available IEC materials on Fe supplementation & $\begin{array}{l}\text { Available IEC materials on Fe supplementation } \\
\text { such as flyers and posters }\end{array}$ \\
\hline Compliance monitoring & $\begin{array}{l}\text { No monitoring form for the use of the village } \\
\text { health workers and the traditional birth attendants }\end{array}$ & $\begin{array}{l}\text { Monitoring notebooks for the use of the village } \\
\text { health workers and the traditional birth attendants }\end{array}$ \\
\hline
\end{tabular}


classified as mild $(\mathrm{Hb} \geq 10$ to $<11 \mathrm{~g} / \mathrm{dl}$ ), moderate $(\mathrm{Hb} \geq 7 \text { to }<10 \mathrm{~g} / \mathrm{dl} \text { ) or severe ( } \mathrm{Hb} \geq 4 \text { to }<7 \mathrm{~g} / \mathrm{dl})^{(20)}$.

House-to-house interviews of pregnant women were carried out by trained nurses and nutritionists to gather information on socio-economic-demographic status; age of gestation; place and frequency of prenatal visits; quantity, quality, source and receipt of Fe supplements; dose and frequency of intake of Fe tablets; and side effects experienced after Fe tablet intake.

\section{Statistical analysis}

Descriptive statistics of baseline characteristics were computed to determine the comparability of the groups using Pearson's $\chi^{2}$ test for categorical variables and twotailed Student's $t$-test for continuous variables. Adequate prenatal visit was defined as 1 visit/month for the first 32 weeks of pregnancy, 1 visit/ 2 weeks from the $33 \mathrm{rd}$ to 36th weeks of pregnancy and weekly visits from the 37 th week up to the time of delivery.

In the present study, two provinces were purposively selected, and from these provinces, two cities and one municipality were chosen based on socio-developmental standing. From each area, three villages were chosen based on geography. Thus, there were both (i) a twolevel nesting (villages were nested within the cities, and cities were nested within the provinces) and (ii) a villagetype and city-type structure.

Because selection of the study sites was not random, multilevel mixed-effects linear regression was used in the analysis, where village and city were random parameters. Village- and city-types were fixed parameters. This was done to determine the effects of the experimental $v$. the control interventions while accounting for possible differences in variances and covariances by area.

Statistical analysis was performed using EpiInfo version 6.04d (Centers for Disease Control and Prevention, Atlanta, GA, USA and WHO, Geneva, Switzerland) and Stata (Stata Corporation, College Station, TX, USA) statistical software packages. Significance was tested at the 5.0\% level.

\section{Ethical approval and informed consent}

The study was reviewed and approved for implementation in Negros Island by the Health Research Division of the Health Policy Development and Planning Bureau of the DOH through the National Center for Disease Prevention and Control and the Regional Health Offices. The purpose of the study and the procedures to be undertaken were explained to the local government and health executives in the provinces of Negros Occidental and Negros Oriental by an NCP staff during courtesy calls and to the pregnant women by trained field assistants during house-to-house visits. Signed informed consent was obtained from each pregnant woman and her husband (if married) or from one of her parents (if unmarried and $<18$ years old).

\section{Results}

There were 596 pregnant women from the experimental area and 584 pregnant women from the control area (or a total of 1180 pregnant women) who agreed to participate in the study (Fig. 1). The participants' mean age was 27 years and $48.1 \%$ were in the second trimester of their pregnancy (Table 2). There was no difference in gestational age between treatment groups at baseline $(P=0 \cdot 276)$ and at post-intervention $(P=0.497)$ and in the number of pregnant women in each trimester at baseline $(P=0 \cdot 418)$ and 6 months after $(P=0 \cdot 786)$. The results were similar even when we limited the analysis to the women in the first half of their pregnancy (data not shown). Nearly all of the pregnant women $(97 \cdot 1 \%)$ remembered their date of the LMP. There were significantly more multiparous women in the experimental area than in the control area both at baseline $\left(76.5\right.$ v. $\left.68.7 \% ; \chi^{2}=4.621, P=0.031\right)$ and at endline (71.5 $\left.v 60.9 \% ; \chi^{2}=7 \cdot 261, P=0.007\right)$. Filipino women's fertility rate is at 3.5 births per woman ${ }^{(21)}$. The 2002 Field Health Service Information Service System report completed by field health workers also showed that there were 18721 recorded number of pregnancies in the experimental areas, higher than the 14905 recorded pregnancies in the control areas ${ }^{(22)}$.

The mean number of prenatal visits per trimester (0.99) $v .1 \cdot 08)$ and the probability of taking Fe tablets $(68.5 v$. $74.3 \%$ ) were not significantly different between the control and experimental areas at baseline (all $P>0 \cdot 05$ ). There were significantly fewer pregnant women in the experimental area with adequate prenatal visits $(13.5 \mathrm{v}$. $23.3 \% ; P=0.002$ ), who were monitored for compliance $\left(43.0 v .52 \cdot 3 \% ; \chi^{2}=5 \cdot 2733, P=0.022\right)$ and who reported having experienced side effects after Fe intake $(20 \cdot 1 v$. $\left.40.0 \% ; \chi^{2}=28 \cdot 0415, P<0.001\right)$ than in the control area at baseline.

Before the implementation of the redesigned ISDS, there were significantly more anaemic pregnant women in the experimental area than in the control area $(50 \cdot 7 v$. $\left.37 \cdot 3 \% ; \chi^{2}=10 \cdot 795, P=0 \cdot 001\right)$. However, at endline, the proportion of anaemic pregnant women in the experimental area was comparable to that of the control area (35.6 v. 33.1\%; $\chi^{2}=0 \cdot 394, P=0 \cdot 530$ ). Although logistic regression showed that the pregnant women in the experimental group were significantly less likely to be anaemic at endline compared with baseline, and whereas the prevalence rates of anaemia did not change in the control group (Table 3), multiple logistic regression taking baseline characteristics, village- and city-type structure, and random effects of nesting into account did not show a significant impact on anaemia prevalence in the intervention area as compared to the control one (Table 4).

When we analysed $\mathrm{Hb}$ concentration as a continuous variable, we saw a significant difference between the control and intervention areas. The mean $\mathrm{Hb}$ concentration of the pregnant women at baseline in the experimental 


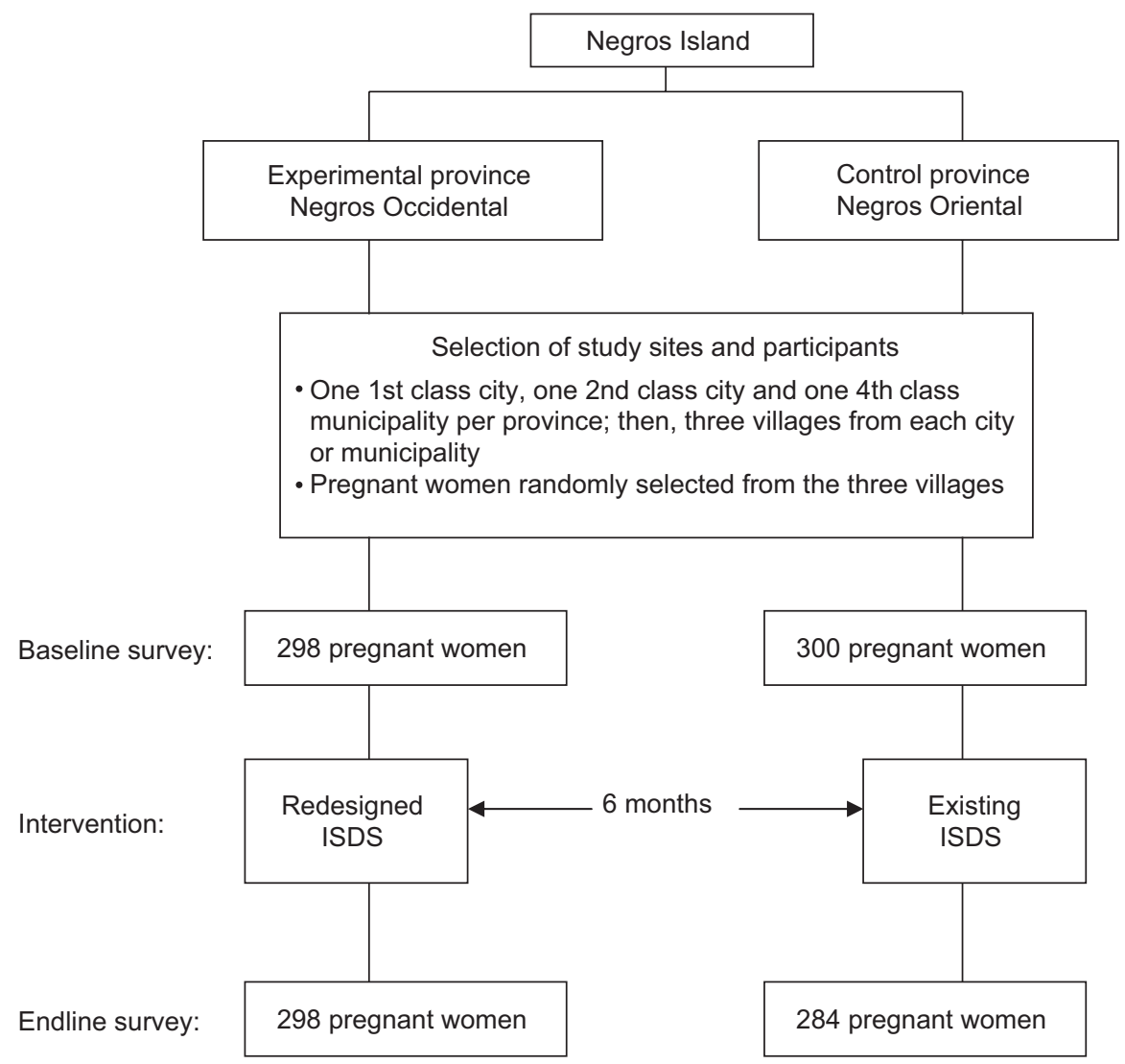

Fig. 1 Study design (ISDS, Fe supplementation delivery system)

Table 2 Characteristics of the participants at baseline and after 6 months by treatment group

\begin{tabular}{|c|c|c|c|c|c|c|}
\hline \multirow[b]{3}{*}{ Variable } & \multicolumn{3}{|c|}{ Baseline } & \multicolumn{3}{|c|}{ Endline } \\
\hline & \multicolumn{2}{|c|}{ Treatment groups } & \multirow[b]{2}{*}{$P^{\star}$} & \multicolumn{2}{|c|}{ Treatment groups } & \multirow[b]{2}{*}{$P+$} \\
\hline & Control & Experimental & & Control & Experimental & \\
\hline$n$ & 300 & 298 & & 284 & 298 & \\
\hline Age, years $(95 \% \mathrm{Cl})$ & $27 \cdot 6(26 \cdot 9,28 \cdot 4)$ & $27 \cdot 7(27 \cdot 0,28 \cdot 5)$ & NS & $27 \cdot 3(26 \cdot 5,28 \cdot 0)$ & $27 \cdot 3(26 \cdot 5,28 \cdot 0)$ & NS \\
\hline Gestational length, weeks $(95 \% \mathrm{Cl})$ & $23 \cdot 7(22 \cdot 7,24 \cdot 8)$ & $24 \cdot 5(23 \cdot 6,25 \cdot 4)$ & NS & $24 \cdot 5(23 \cdot 3,25 \cdot 7)$ & $25 \cdot 1(24 \cdot 0,26 \cdot 2)$ & NS \\
\hline \multicolumn{7}{|l|}{ Gravida (\%) } \\
\hline Primipara & $31 \cdot 3$ & $23 \cdot 5$ & 0.031 & $39 \cdot 1$ & $28 \cdot 5$ & 0.007 \\
\hline Multiparous & $68 \cdot 7$ & $76 \cdot 5$ & & $60 \cdot 9$ & $71 \cdot 5$ & \\
\hline Mean $(95 \% \mathrm{Cl}) \mathrm{Hb}(\mathrm{g} / \mathrm{dl})$ & $11 \cdot 4(11 \cdot 2,11 \cdot 6)$ & $10 \cdot 8(10 \cdot 6,10 \cdot 9)$ & $<0.001$ & $11 \cdot 5(11 \cdot 3,11 \cdot 6)$ & $11 \cdot 3(11 \cdot 2,11 \cdot 5)$ & NS \\
\hline Anaemia prevalence (\%) & $37 \cdot 3$ & $50 \cdot 7$ & $0 \cdot 001$ & $33 \cdot 1$ & $35 \cdot 6$ & NS \\
\hline Normal & $62 \cdot 7$ & $49 \cdot 3$ & & $66 \cdot 9$ & $64 \cdot 6$ & \\
\hline Mild & $22 \cdot 7$ & $22 \cdot 1$ & & $20 \cdot 8$ & $20 \cdot 8$ & \\
\hline Moderate & $14 \cdot 0$ & $24 \cdot 8$ & & $11 \cdot 3$ & $13 \cdot 1$ & \\
\hline Severe & $0 \cdot 7$ & $3 \cdot 7$ & & $0 \cdot 7$ & $1 \cdot 7$ & \\
\hline No. of prenatal visits per trimester & $1.08(0.96,1.20)$ & $0.99(0.91,1.07)$ & NS & $1.04(0.91,1.16)$ & $1.66(1.52,1 \cdot 80)$ & $<0.001$ \\
\hline With adequate no. of prenatal visits (\%) & $23 \cdot 3$ & $13 \cdot 5$ & 0.002 & $21 \cdot 2$ & $17 \cdot 8$ & NS \\
\hline Currently taking $\mathrm{Fe}$ tablets (\%) & $74 \cdot 3$ & $68 \cdot 5$ & NS & $57 \cdot 4$ & $79 \cdot 2$ & $<0.001$ \\
\hline Proportion monitored for compliance (\%) & $52 \cdot 3$ & $43 \cdot 0$ & 0.022 & $29 \cdot 2$ & $77 \cdot 2$ & $<0.001$ \\
\hline Proportion with reported side-effects (\%) & $40 \cdot 0$ & $20 \cdot 1$ & $<0.001$ & $23 \cdot 8$ & $34 \cdot 7$ & 0.019 \\
\hline
\end{tabular}

${ }^{*}$ Comparison between groups at baseline.

tComparison between groups at endline.

group $(10 \cdot 87 \mathrm{~g} / \mathrm{dl})$ was lower than in the control group $(11.45 \mathrm{~g} / \mathrm{dl} ; P=0.001)$ but not at endline $(P>0.05)$. After controlling for baseline characteristics, village- and citytype structure, and random effects of nesting, an increase in the mean $\mathrm{Hb}$ among pregnant women in the experi- mental group by $0 \cdot 49 \mathrm{~g} / \mathrm{dl}(95 \% \mathrm{CI} 0 \cdot 16,0 \cdot 78 ; P=0 \cdot 002)$ more than in the control group was observed. There were significantly more pregnant women in the experimental group than in the control group who were taking $\mathrm{Fe}$ tablets at endline $\left(79 \cdot 2 v \cdot 57 \cdot 4 \% ; \chi^{2}=32 \cdot 060 ; P<0 \cdot 001\right)$. 
Table 3 Odds ratios of outcomes between baseline and 6 months post-intervention shown separately for the control and intervention areas

\begin{tabular}{|c|c|c|c|c|c|c|c|}
\hline Survey period & Yes & No & Odds & $95 \% \mathrm{Cl}$ & OR & $95 \% \mathrm{Cl}$ & $P$ \\
\hline \multicolumn{8}{|l|}{ Control areas } \\
\hline \multicolumn{8}{|l|}{ Anaemia } \\
\hline Baseline & 112 & 188 & 0.60 & $0 \cdot 47,0 \cdot 75$ & $1 \cdot 00$ & & \\
\hline Endline & 93 & 191 & 0.49 & $0.38,0.62$ & $0 \cdot 82$ & $0 \cdot 58,1 \cdot 15$ & NS \\
\hline \multicolumn{8}{|c|}{ Moderate anaemia } \\
\hline Baseline & 42 & 258 & $0 \cdot 16$ & $0 \cdot 12,0.23$ & 1.00 & & \\
\hline Endline & 32 & 252 & $0 \cdot 13$ & $0.09,0 \cdot 18$ & 0.78 & $0 \cdot 4,1 \cdot 28$ & NS \\
\hline \multicolumn{8}{|c|}{ Severe anaemia } \\
\hline Baseline & 2 & 298 & 0.01 & $0.00,0.03$ & $1 \cdot 00$ & & \\
\hline Endline & 2 & 282 & 0.01 & $0.00,0.03$ & 1.06 & $0 \cdot 15,7 \cdot 57$ & NS \\
\hline \multicolumn{8}{|c|}{ Adequate prenatal check-ups } \\
\hline Baseline & 68 & 228 & $0 \cdot 30$ & $0.23,0.39$ & $1 \cdot 00$ & & \\
\hline Endline & 57 & 212 & $0 \cdot 27$ & $0.20,0.36$ & 0.90 & $0.60,1 \cdot 34$ & \\
\hline \multicolumn{8}{|c|}{ Taking supplements } \\
\hline Baseline & 223 & 77 & $2 \cdot 90$ & $2 \cdot 24,3 \cdot 75$ & 1.00 & & \\
\hline Endline & 163 & 121 & $1 \cdot 35$ & $1 \cdot 06,1 \cdot 70$ & 0.47 & $0.33,0.66$ & $<0.001$ \\
\hline \multicolumn{8}{|c|}{ Being monitored } \\
\hline Baseline & 157 & 143 & $1 \cdot 10$ & $0 \cdot 88,1 \cdot 38$ & 1.00 & & \\
\hline Endline & 83 & 201 & $0 \cdot 41$ & $0.32,0.53$ & 0.38 & $0.26,0.53$ & $<0.001$ \\
\hline \multicolumn{8}{|c|}{ Reported side-effects } \\
\hline Baseline & 120 & 180 & 0.67 & $0.53,0.84$ & 1.00 & & \\
\hline Endline & 38 & 122 & $0 \cdot 31$ & $0.22,0.45$ & 0.47 & $0 \cdot 30,0 \cdot 72$ & 0.001 \\
\hline \multicolumn{8}{|c|}{ Experimental areas } \\
\hline \multicolumn{8}{|l|}{ Anaemia } \\
\hline Baseline & 151 & 147 & 1.03 & $0 \cdot 82,1 \cdot 29$ & 1.00 & & \\
\hline Endline & 106 & 192 & 0.55 & $0.44,0.70$ & 0.54 & $0.39,0.75$ & $<0.001$ \\
\hline \multicolumn{8}{|c|}{ Moderate anaemia } \\
\hline Baseline & 74 & 224 & 0.33 & $0.25,0.43$ & 1.00 & & \\
\hline Endline & 39 & 259 & 0.15 & $0.11,0.21$ & 0.46 & $0 \cdot 30,0 \cdot 70$ & $<0.001$ \\
\hline \multicolumn{8}{|c|}{ Severe anaemia } \\
\hline Baseline & 11 & 287 & 0.04 & $0.02,0.07$ & $1 \cdot 00$ & & \\
\hline Endline & 5 & 293 & 0.02 & $0.01,0.04$ & 0.45 & $0 \cdot 15,1 \cdot 30$ & NS \\
\hline \multicolumn{8}{|c|}{ Adequate prenatal check-ups } \\
\hline Baseline & 39 & 257 & $0 \cdot 15$ & $0 \cdot 11,0 \cdot 21$ & 1.00 & & \\
\hline Endline & 49 & 227 & 0.22 & $0 \cdot 16,0.29$ & $1 \cdot 42$ & $0.90,2.25$ & NS \\
\hline \multicolumn{8}{|c|}{ Taking supplements } \\
\hline Baseline & 204 & 94 & $2 \cdot 17$ & $1 \cdot 70,2 \cdot 77$ & $1 \cdot 00$ & & \\
\hline Endline & 236 & 62 & $3 \cdot 81$ & $2 \cdot 88,5 \cdot 03$ & $1 \cdot 75$ & $1 \cdot 21,2 \cdot 55$ & 0.003 \\
\hline \multicolumn{8}{|c|}{ Being monitored } \\
\hline Baseline & 128 & 170 & 0.75 & $0.60,0.95$ & $1 \cdot 00$ & & \\
\hline Endline & 230 & 68 & $3 \cdot 38$ & $2 \cdot 58,4 \cdot 43$ & $4 \cdot 49$ & $3 \cdot 08,6 \cdot 56$ & $<0.001$ \\
\hline \multicolumn{8}{|c|}{ Reported side-effects } \\
\hline Baseline & 60 & 238 & 0.25 & $0 \cdot 19,0 \cdot 33$ & $1 \cdot 00$ & & \\
\hline Endline & 82 & 154 & 0.53 & $0 \cdot 41,0 \cdot 70$ & $2 \cdot 11$ & $1 \cdot 42,3 \cdot 14$ & $<0.001$ \\
\hline
\end{tabular}

Overall, only one-fifth of the pregnant women had an adequate number of prenatal visits at baseline $(18 \cdot 1 \%)$ and at post-intervention $(19 \cdot 4 \%)$. At baseline, the proportion of pregnant women in the experimental area with adequate prenatal visits was significantly less than in the control area $(13.2 v \cdot 23.0 \% ; P=0.002)$. However, the proportion of pregnant women with adequate prenatal visits increased in the experimental group and was comparable to the control group at post-intervention $(17 \cdot 8 v .21 \cdot 2 \% ; P=0 \cdot 311)$. Although the proportion of pregnant women with adequate prenatal visits was generally very low, the actual number of prenatal visits/trimester of gestation increased almost twofold (by $0.69 ; P<0 \cdot 001$ ) in the experimental group (0.99 to 1.66 visits/trimester of gestation at baseline to endline; $P<0 \cdot 001)$ while it remained at baseline level in the control group ( 1.08 to 1.04 visits/trimester; $P=0.617$ ). Pregnant women from the experimental group were also four times more likely to be taking Fe tablets, five times more likely to report side effects from Fe intake and sixteen times more likely to be monitored for compliance to Fe supplementation compared to those from the control area. An increase in the reporting of side effects in the experimental group at endline (as shown in Table 2) manifests the increase in the client-health provider contact, concurrent with an increase in the proportion of pregnant women who were monitored by the health workers.

\section{Discussion}

For the past decades, prenatal Fe supplementation has been the standard recommendation for reducing maternal anaemia in developing countries including the Philippines. This strategy has long been documented as efficacious in improving Fe status. A meta-analysis of data on the relative 
change in maternal $\mathrm{Hb}$ associated with Fe supplementation from pooled randomised controlled trials published between 1966 and 1998 showed that Fe supplementation increased the $\mathrm{Hb}$ concentration of pregnant women ${ }^{(23)}$. A review of forty randomised or quasi-controlled trials involving 12706 pregnant women showed that daily Fe supplement increases $\mathrm{Hb}$ levels in both antenatal and postnatal maternal blood ${ }^{(24)}$. Reduction in anaemia prevalence after supplementing with Fe was also seen among pregnant women in India ${ }^{(25)}$, in rural Bangladesh ${ }^{(26)}$ and in adolescent pregnant women in their first pregnancy in Wisconsin, $\mathrm{USA}^{(27)}$.

Table 4 Odds ratios for the impact of the intervention on the experimental group in comparison to the control group at endline as compared to baseline

\begin{tabular}{|c|c|c|c|}
\hline Treatment areas & OR & $95 \% \mathrm{Cl}$ & $P$-value \\
\hline \multicolumn{4}{|l|}{ Anaemia } \\
\hline Control & $1 \cdot 00$ & & \\
\hline Experimental & 0.67 & $0.41,1.09$ & NS \\
\hline \multicolumn{4}{|l|}{ Moderate anaemia } \\
\hline Control & 1.00 & & \\
\hline Experimental & 0.58 & $0 \cdot 30,1 \cdot 15$ & NS \\
\hline \multicolumn{4}{|l|}{ Severe anaemia } \\
\hline Control & 1.00 & & \\
\hline Experimental & $0 \cdot 40$ & $0 \cdot 04,3 \cdot 85$ & NS \\
\hline \multicolumn{4}{|c|}{ Adequate prenatal check-ups } \\
\hline Control & 1.00 & & \\
\hline Experimental & 1.56 & $1 \cdot 16,2 \cdot 11$ & 0.004 \\
\hline \multicolumn{4}{|c|}{ Taking iron supplements } \\
\hline Control & $1 \cdot 00$ & & \\
\hline Experimental & $3 \cdot 79$ & $2 \cdot 22,6 \cdot 49$ & $<0.001$ \\
\hline \multicolumn{4}{|l|}{ Being monitored } \\
\hline Control & $1 \cdot 00$ & & \\
\hline Experimental & $16 \cdot 86$ & $9 \cdot 83,28 \cdot 93$ & $<0.001$ \\
\hline \multicolumn{4}{|c|}{ Reported side-effects } \\
\hline Control & $1 \cdot 00$ & & \\
\hline Experimental & $5 \cdot 39$ & $2 \cdot 90,10 \cdot 03$ & $<0.001$ \\
\hline
\end{tabular}

The problem, then, was not in the efficacy of the Fe tablets but in the effectiveness of the public health intervention. The redesigned ISDS was developed to answer the identified problems and constraints in the existing ISDS. An innovative approach to addressing some of the constraints was empowering and elevating the status of the local VHW as partners of the professional health workers in the delivery of health services. Responsibilities that would normally go to the overworked professional health workers were given to the local health workers such as identification and registration of pregnant women, counselling with the use of the IEC materials, distribution of the Fe supplements and monitoring compliance of the pregnant women in their assigned clusters with the use of the monitoring notebooks. With appropriate training and motivation, indigenous health workers became effective channels for the Fe supplementation scheme for pregnant women as was similarly seen in Indonesia ${ }^{(17,28,29)}$.

Compliance is a key factor to the success of an ISDS. Side effects experienced by the pregnant women after Fe tablet intake might be a deterrent to compliance, resulting in the inability of the pregnant women to complete the minimum required number of Fe supplements to be taken during pregnancy. An increase in compliance was noted despite the increase in the proportion of pregnant women in the experimental group who reported minor gastrointestinal side effects. This could be attributed to the increase in the proportion of pregnant women who were visited, counselled and monitored by the health workers, which led to an increase in the reporting of side effects concomitant with an increase in the awareness of the need of Fe supplements during pregnancy, leading to persistence in daily Fe tablet intake ${ }^{(17,30)}$. Although the

Table 5 Suggested changes and ways to improve iron supplementation programmes

What is to be done

Empowering the indigenous health workers

Improving the system of monitoring, reporting and evaluation

Enhancing the target's awareness

Enhancing the health worker-client relationship (Kumare or sisterhood strategy)

Enhancing awareness of the local government and health unit executives

Assuring availability of supplies and quality Fe supplements

Encouraging community ownership and community action to ensure programme sustainability
Training on Fe distribution, compliance monitoring, counselling, recording, reporting and referrals

Providing the indigenous health workers with monitoring notebooks Conducting periodic household surveys, spot mapping, clustering to improve the registration and referral of pregnant women

Innovating mothers' class and one-on-one counselling (pass on the flyer to a newly identified pregnant woman) to involve more the pregnant mothers

Creating clusters of twenty to thirty households manned by one health worker

Improving the process of conducting and the frequency of home visits by the health workers

Motivating and creating community awareness on the importance of $\mathrm{Fe}$ supplementation and pre- and postnatal care through increased community public health campaigns

Creating a quality monitoring board to assure competitive procurement and of standard Fe supplements

Actual targeting (based on the updated cluster records) when procuring Fe supplements to avoid underestimation of Fe need

Assure buffer Fe supply

Training on actual targeting, social marketing and monitoring quality 
giving of $\mathrm{Fe}$ supplements to pregnant women in the redesigned ISDS was not directly observed by the supplementers due to logistical constraints, the attendant increase in $\mathrm{Hb}$ concentration makes the present study result a reliable measure of compliance to $\mathrm{Fe}$ tablet intake.

An increase in the actual number of prenatal visits of pregnant women in the group supplemented with Fe through the redesigned ISDS was also noted. Early detection of pregnancy by the indigenous health workers through clustering of households and listing of pregnant women led to early counselling and referral of the pregnant women for prenatal check-up and start of Fe supplementation. However, because the proportion of women with adequate number of prenatal visits remained low, improvements on this system could be iteratively added and evaluated.

In summary, we recommend the use of an ISDS that empowers the local VHW to become partners of the professional health care workers in registration, counselling, Fe supplement distribution and monitoring compliance of pregnant women with appropriate training. We have shown this to be an effective system in increasing maternal $\mathrm{Hb}$ concentration and in improving prenatal health-seeking behaviour. A summary of suggested changes and ways to improve Fe supplementation programmes is provided in Table 5 .

\section{Acknowledgements}

Sources of funding: The study was funded by the National Center for Disease Prevention and Control of the Philippine Department of Health.

Conflict of interest: None of the authors had any conflict of interest.

Authorship responsibilities: M.G.D.R. was responsible for the management of the project and wrote the manuscript. P.R.-S. performed the statistical analyses, interpreted the data and reviewed the manuscript. L.W.T. reviewed the manuscript. J.N.S. was involved in the design of the study; performed the statistical analyses and reviewed the manuscript. L.S.P. was involved in the design of the study and reviewed the manuscript. F.S.S. was responsible for the overall conception and design of the study and reviewed the manuscript.

\section{References}

1. McLean E, Cogswell M, Egli I, Wojdyla D \& de Benoist B (2007) Worldwide prevalence of anemia in preschool aged children, pregnant women and non-pregnant women of reproductive age. In Nutritional Anemia [K Kraemer and S Zimmermann, editors]. Basel, Switzerland: Sight and Life Press; available at http://www.sightandlife.org/SAL_NutA/ SAL_NA_Chap01.pdf

2. Food and Nutrition Research Institute (2003) Sixth National Nutrition Survey. Taguig: FNRI.

3. Food and Nutrition Research Institute (1998) Fifth National Nutrition Survey. Taguig: FNRI.
4. Food and Nutrition Research Institute (1993) Fourth National Nutrition Survey. Taguig: FNRI.

5. Casanueva E \& Viteri FE (2003) Iron and oxidative stress in pregnancy. J Nutr 133, 1700S-1708S.

6. Beard JL (2000) Effectiveness and strategies of Fe supplementation during pregnancy. Am J Clin Nutr $\mathbf{7 1}$, 1288S-1294S.

7. Stoltzfus R \& Dreyfuss M (1998) Guidelines for the use of Fe supplements to prevent and treat $\mathrm{Fe}$ deficiency anemia. International Nutritional Anemia Consultative Group, World Health Organization, United Nations Children's Fund. Washington, DC: ILSI Press.

8. Bonnar J, Goldberg A \& Smith JA (1969) Do pregnant women take their Fe? Lancet 1, 457-458.

9. Mannar MGV (2007) The case for urgent action to address nutritional anemia. In Nutritional Anemia [K Kraemer and S Zimmermann, editors]. Basel, Switzerland: Sight and Life Press; available at http://www.sightandlife.org/SAL_NutA/ SAL_NA_Chap02.pdf

10. Galloway R \& McGuire J (1994) Determinants of compliance with Fe supplementation: supplies, side effects, or psychology? Soc Sci Med 39, 381-390.

11. Schultink W, van der Ree M, Matulessi P \& Gross R (1993) Low compliance with an Fe-supplementation program: a study among pregnant women in Jakarta, Indonesia. Am J Clin Nutr 57, 135-139.

12. Yip R (2002) Iron supplementation: country level experiences and lessons learned. J Nutr 132, 859S-861S.

13. Yip R \& Ramakrishnan U (2002) Experiences and challenges in developing countries. J Nutr 132, 827S-830S.

14. DeMaeyer EM, Dallman P, Gurney JM, Hallberg L, Sood SK \& Srikantia SG (1989) Preventing and Controlling Iron Deficiency Anemia through Primary Health Care. Geneva: WHO

15. Charoenlarp P, Dhanamitta S, Kaewvichit R et al. (1988) A WHO collaborative study on Fe supplementation in Burma and in Thailand. Am J Clin Nutr 47, 280-297.

16. Schultink W (1996) Iron supplementation programmes: compliance of target groups and frequency of tablet intake. Food Nutr Bull 17, 22-26.

17. Galloway R, Dusch E, Elder L et al. (2002) Women's perceptions of Fe deficiency and anemia prevention and control in eight developing countries. Soc Sci Med 55, 529-544.

18. Yip R (1996) Iron supplementation during pregnancy: is it effective? Am J Clin Nutr 63, 853-855.

19. Republic Act No. 7160 (1991) An act providing for the Local Government Code of 1991. October 10, Manila, Philippines.

20. Mathers CD, Bernard C, Iburg KM et al. (2003) Global Burden of Disease in 2002: Data Sources, Methods and Results. Global Programme on Evidence for Health Policy Discussion Paper no. 54. Geneva: WHO.

21. National Statistics Office (2003) National Demographic and Health Survey. Summary of Findings. Manila, Philippines: NSO; available at http://www.census.gov.ph/hhld/ndhs_ 2003.html

22. Department of Health (2002) Natality Report by Region and Province. Manila, Philippines: DOH; available at http:// doh.gov.ph/data_stat/html/fhsis/natality_birthsbypregnancy. pdf

23. Sloan NL, Jordan E \& Winikoff B (2002) Effects of Fe supplementation on maternal hematologic status in pregnancy. Am J Publ Health 92, 288-293.

24. Pena-Rosas JP, Viteri FE (2006) Effects of routine oral Fe supplementation with or without folic acid for women during pregnancy (Review). Cochrane Database Syst Rev issue 3, CD004736. DOI: 10.1002/14651858.CD004736.pub2

25. Abel R, Rajaratnam J, Kalaimani A \& Kirubakaran S (2000) Can Fe status be improved in each of the three trimesters? A community-based study. Eur J Clin Nutr 54, 490-493. 
26. Ekstrom EC, Hyder SM, Chowdhury AM et al. (2002) Efficacy and trial effectiveness of weekly and daily $\mathrm{Fe}$ supplementation among pregnant women in rural Bangladesh: disentangling the issues. Am J Clin Nutr 76, 1392-1400.

27. Meier PR, Nickerson HJ, Olson KA, Berg RL \& Meyer JA (2003) Prevention of Fe deficiency anemia in adolescent and adult pregnancies. Clin Med Res 1, 29-36.

28. Robinson SJ (1998) Using Traditional Birth Attendants to Improve Iron Tablet Utilization by Pregnant Women:
Maluku Province, Indonesia. MotherCare Technical Working Paper no. 8. Arlington, VA: MotherCare Project, John Snow Inc.

29. Utomo B, Riono P, Budiono T et al. (1993) The Alleviation of Maternal Anemia in Indramayu Regency, Indonesia: The Result from the MotherCare Project. MotherCare Project Working Paper no. 23. Arlington, VA: MotherCare Project, John Snow, Inc.

30. Elder LK (2000) Issues in Programming for Maternal Anemia. Arlington, VA: MotherCare Project, John Snow Inc. 